\title{
Treatment of model oily produced water by combined pre-ozonation-microfiltration process
}

\section{Zsolt László Kiss, Ildikó Kovács, Gábor Veréb, Cecilia Hodúr \& Zsuzsanna László}

To cite this article: Zsolt László Kiss, Ildikó Kovács, Gábor Veréb, Cecilia Hodúr \& Zsuzsanna László (2015): Treatment of model oily produced water by combined pre-ozonation-microfiltration process, Desalination and Water Treatment, DOI: 10.1080/19443994.2015.1109754

To link to this article: http://dx.doi.org/10.1080/19443994.2015.1109754

曲 Published online: 03 Nov 2015.

Submit your article to this journal ¿

山 Article views: 2

Q View related articles $\square$

View Crossmark data ¿ 


\title{
Treatment of model oily produced water by combined pre-ozonation-microfiltration process
}

\author{
Zsolt László Kiss, Ildikó Kovács, Gábor Veréb, Cecilia Hodúr, Zsuzsanna László* \\ Faculty of Engineering, University of Szeged, Moszkvai krt. 9, H-6725 Szeged, Hungary, Tel. +36 62 546561; \\ email: zsizsu@mk.u-szeged.hu (Z. László)
}

Received 30 March 2015; Accepted 11 October 2015

\begin{abstract}
Oily wastewaters are one of the major environmental pollutants in aquatic systems. This is due to the emission of a variety of industrial oily wastewaters from sources such as crude oil mining (production), refineries, petrochemical plants and transportation. The aims of this work were to investigate the treatment of oil-contaminated wastewaters with a preozonation/microfiltration combined system and the effect of pre-ozonation on the microfiltration parameters. The results demonstrated that ozone pre-treatment modified the chemical nature ( $\mathrm{pH}$ and conductivity) of oil-in-water emulsion, resulting in higher wettability of the polyethersulphone membrane. In case of salt-containing model emulsions compared to pure oil emulsions, ozone treatment was found to be more effective for membrane resistance reduction and in chemical oxygen demand retention.
\end{abstract}

Keywords: Oilfield-produced water; Microfiltration; Ozone treatment; Oil drop size

\section{Introduction}

Industrial oil-containing wastewaters are one of the main pollutants of natural waters, changing water characteristics by its potentially toxic organic and inorganic matter content [1]. The crude oil is a complex mixture of salts and hydrocarbons containing heteroatoms such as nitrogen-, sulphur- and oxygen-forming acidic compounds contributing to the acidity of the crude oil. The organic acids (C6-C12) behave as natural emulsifiers stabilising water-in-oil emulsions. These compounds can migrate into the water phase causing acidic character of crude oil-in-water emulsions [2].

${ }^{*}$ Corresponding author.
The typical feed concentrations vary from 50 to $1,000 \mathrm{ppm}$ of oil [3]. Many technologies have been used for oil-in-water emulsion purification, such as ultrasonic separation, coagulation, air flotation, heating, ozonation, flocculation and membrane filtration [4]. Among the membrane filtration processes, the ultrafiltration (UF) is the most effective treatment for oily wastewater possessing by high oil removal efficiency, no necessity for chemical additives and relatively low energy costs [4]. However, microfiltration (MF) has lower elimination efficiency, even so it becomes gradually an alternative technology for oil/water separation [5-15]. Membrane separation processes combined with pre-treatments may enhance the elimination efficiency, and reduce the membrane

Presented at EuroMed 2015: Desalination for Clean Water and Energy Palermo, Italy, 10-14 May 2015.

Organized by the European Desalination Society.

1944-3994/1944-3986 @ 2015 Balaban Desalination Publications. All rights reserved. 
resistance. Pre-oxidation degrades the organic pollutants in oily wastewaters, and in parallel it may improve the flocculation efficiency and particle removal during the filtration step [16,17].

This work aims to investigate the effect of pre-ozonation on the properties of oil-in-water emulsions. MF studies were targeted to describe the effect of pre-ozonation on the filtration parameters (i.e. flux, filtration resistances and oil rejection) in absence and presence of salts in case of oil-in-water emulsions. Additionally, fouling mechanisms (during MF) were analysed and modelled, using experimental flux decline data.

\section{Materials and methods}

\subsection{Materials}

A model oil-in-water emulsion (0.01 wt.\%) was prepared from crude oil (Algyő, Hungary) and distilled water using ultrasonication for $20 \mathrm{~min}$ (UP $100 \mathrm{H}$ Ultrasonic processor, Hielscher, Germany). A salt-containing model oil-in-water emulsion was also prepared (Table 1). The composition of the model water represents a typical underground water composition in the South Plain in Hungary.

\subsection{Experimental design}

The oil-in-water emulsions were treated with ozone for a given time and the treated solutions were then promptly used as the feed in the MF experiments. Ozone was produced from oxygen (Linde, 3.5) using a flow-type ozone generator (BMT 802X, Germany). The ozone-containing gas was bubbled continuously through a batch reactor during the treatment. The volume of treated water was $500 \mathrm{~mL}$ and the gas flow rate was $1 \mathrm{~L} \mathrm{~min}^{-1}$. The ozone concentration in the gas was measured before and after the reactor using a UV spectrophotometer (WPA Biowave II) at $\lambda=254 \mathrm{~nm}$. In order to avoid the damage of the

Table 1

Salt content of model oil-in-water emulsion

\begin{tabular}{ll}
\hline Salt content & Concentration $\left(\mathrm{mg} \mathrm{L}^{-1}\right)$ \\
\hline $\mathrm{NaHCO}_{3}$ & $2,259.87$ \\
$\mathrm{NH}_{4} \mathrm{Cl}$ & 53.49 \\
$\mathrm{FeCl}_{3}$ & 2.7 \\
$\mathrm{CaCl}_{2}$ & 19.11 \\
$\mathrm{MgSO}_{4}$ & 17.25 \\
$\mathrm{KCl}$ & 20.88 \\
$\mathrm{NaCl}$ & 93.5 \\
\hline
\end{tabular}

membrane by residual ozone, it was removed from emulsions by bubbling oxygen before membrane filtration. The membrane filtration experiments were carried out in a batch-stirred cell (Millipore, XFUF04701) with a capacity of $50 \mathrm{~mL}$. Flat-sheet polyethersulfone (PES) membranes with a pore size of $0.2 \mu \mathrm{m}$ (PL series, Millipore) and a membrane effective area of $0.001734 \mathrm{~m}^{2}$ were applied. Before each $\mathrm{MF}$ experiment, the membrane was immersed in distilled water overnight. The initial feed volume was $50 \mathrm{~mL}$ and the experiments were carried out at $10 \mathrm{kPa}$ until $40 \mathrm{~mL}$ of the total sample had been filtered at a stirring speed of $50 \mathrm{rpm}$. Determination of the chemical oxygen demand (COD) was based on the standard method, which involves potassium dichromate oxidation. For the analyses, standard test tubes (Lovibond) were used. The digestions were carried out in a COD digester (Lovibond, ET 108) and the COD values were measured with a COD photometer (Lovibond PCCheckIt). Viscosity measurements were carried out with a Vibro viscometer (AND SV-10 A\&D Company, Japan) in a temperature-controlled water bath (Cole Palmer, USA) at constant temperature of $25.0 \pm 0.1^{\circ} \mathrm{C}$. Membrane hydrophobicity was quantified by measuring the contact angle that was formed between the membrane surface (before and after filtration of solutions) and distilled water. Contact angles were measured using the sessile drop method (Datapysics Contact Angle System OCA15Pro, Germany).

\subsection{Fouling model}

\subsubsection{Resistance-in-series model}

The membrane resistance $\left(R_{\mathrm{M}}\right)$ was calculated as [18] follows:

$R_{\mathrm{M}}=\frac{\Delta p}{J_{\mathrm{w}} \eta_{\mathrm{w}}}\left(\mathrm{m}^{-1}\right)$

where $\Delta p$ is the pressure difference between the two sides of the membrane $(\mathrm{Pa}), J_{\mathrm{w}}$ is the water flux of the clean membrane and $\eta_{\mathrm{w}}$ is the viscosity of the water (Pa s).

The fouling resistance $\left(R_{\mathrm{F}}\right)$ was determined by measuring the water flux through the membrane after the filtration of oil-in-water emulsion and rinsing it with distilled water to remove any particles of residue layer from the surface, by subtracting the resistance of the clean membrane:

$R_{\mathrm{F}}=\frac{\Delta p}{J_{\mathrm{WA}} \eta_{\mathrm{w}}}-R_{\mathrm{M}}$ 
where $J_{\mathrm{WA}}$ is the water flux after the rinsing.

The resistance of the polarisation layer $\left(R_{\mathrm{P}}\right)$ can be calculated as follows:

$R_{\mathrm{P}}=\frac{\Delta p}{J_{\mathrm{c}} \eta_{\mathrm{WW}}}-R_{\mathrm{F}}-R_{\mathrm{M}}$

where $R_{P}$ is the polarisation layer resistance $\left(\mathrm{m}^{-1}\right), R_{\mathrm{F}}$ is the fouling resistance (mainly by the fouled pores) $\left(\mathrm{m}^{-1}\right), J_{\mathrm{c}}$ is the constant flux at the end of the concentration and $\eta_{\mathrm{WW}}$ is the wastewater viscosity.

The total resistance $\left(R_{\mathrm{T}} ;\left(\mathrm{m}^{-1}\right)\right)$, can be evaluated from the steady-state flux using the resistance-in-series model:

$R_{\mathrm{T}}=R_{\mathrm{M}}+R_{\mathrm{F}}+R_{\mathrm{P}}$

The volume reduction ratio (VRR) can be determined using the following equation:

$\mathrm{VRR}=\frac{V_{\text {feed }}}{V_{\text {feed }}-V_{\text {perm }}}$

where $V_{\text {feed }}$ is the feed volume $(\mathrm{mL})$ and $V_{\text {perm }}$ is the permeate volume $(\mathrm{mL})$.

The selectivity of a membrane for a given solute can be expressed by the average retention $(R)$ :

$R=\left(1-\frac{c}{c_{0}}\right) \times 100 \%$

where $c$ is the average concentration of the solute in the permeate phase and $c_{0}$ is the concentration of the solute in the feed.

\section{Results and discussion}

\subsection{Effect of pre-ozonation}

In the first series of experiments, the effect of ozone treatment on the crude oil-in-water emulsions (in absence and in presence of salts) was investigated. The amounts of absorbed ozone at different ozonation times are presented in Table 2 .

Due to the crude oil's complex composition, it may contain acids causing lower $\mathrm{pH}(\mathrm{pH} 5.97$ in $100 \mathrm{ppm}$ emulsions without salts). It was found that in the absence of salts the conductivity and the $\mathrm{pH}$ significantly changed during ozone treatment. The $\mathrm{pH}$ increased with short-time ozonation (Fig. 1(a)) - in parallel with increasing conductivity-due to the appearance of oxidation by-products, like aldehydes and ketones formed from hydrocarbons, and oxidisation of small organic compounds. The further ozonation may result the production of small organic acids (e.g. oxalic acid) and carbon dioxide originated from the degradation of hydrocarbons causing decrease in $\mathrm{pH}$, and decrease in conductivity. These phenomena cannot be observed in salt-containing model emulsions (Fig. 1(b)), because of their high conductivity $\left(\sim 2 \mathrm{mS} \mathrm{cm}^{-1}\right)$, which is much higher than the change caused by the ozone treatment $\left(\sim 20 \mu \mathrm{S} \mathrm{cm}^{-1}\right)$. The salt-containing emulsions have a buffering effect, thus the change of $\mathrm{pH}$ caused by ozone treatment also cannot be observed.

As it was expected, the ozone treatment effectively decreased the COD value. The turbidity also decreased during ozonation both in presence and absence of salt due to decreasing of oil content (Fig. 2). On the other hand, the ozone treatment resulted in slight decrease in droplet sizes (Fig. 3), which should cause increased turbidity; the slight changes in turbidity at higher amounts of absorbed ozone may be a resultant sum of opposite effects.

The stability of oil-in-water emulsions-according to the double layer theory-strongly depends on the electrolyte content of the solvent medium affecting the zeta potential and therefore the electrostatic interactions and the droplet size distribution [19]. The mean droplet sizes of $100 \mathrm{ppm}$ crude oil emulsions were found to be higher in presence of salts due to the double layer theory (Fig. 3(a)). The ratios of the droplets larger than $0.2 \mu \mathrm{m}$ (the pore size of the membrane) also decreased by ozonation time both in presence and absence of salts (Fig. 3(b)).

\subsection{Effect of pre-ozonation on $M F$}

In the next series of experiments, the pre-ozonated crude oil emulsions were filtered through $0.2 \mu \mathrm{m}$ PES membranes. It was found that the permeate fluxes of pre-ozonated samples were higher than fluxes of untreated emulsions (Fig. 4(a)) in absence of salts.

Analysing the results obtained by resistancesin-series model, it was found that the crude oil emulsion filtration caused higher polarisation layer resistance than pre-ozonated samples. In the case of filtration of ozonated crude oil emulsions, lower polarisation layer resistances were obtained (Fig. 4(b)). It can be explained by the effect of ozonisation; the ozonation by-products may stabilise the oil droplets in the emulsion (in accordance with in the decreasing droplet sizes (Fig. 3(a)).

The effect of ozonation on the fluxes was different depending on the presence or absence of salts. 12-min ozone treatment decreased the flux; however, after 
Table 2

Ozonation times and amounts of absorbed ozone $\left(\mathrm{mg} \mathrm{L}^{-1}\right)$

\begin{tabular}{llllll}
\hline & $4 \mathrm{~min} \mathrm{O}_{3}$ & $8 \mathrm{~min} \mathrm{O}_{3}$ & $12 \mathrm{~min} \mathrm{O}_{3}$ & $16 \mathrm{~min}_{3}$ & $20 \mathrm{~min}_{3}$ \\
\hline Crude oil & 7.9 & 28.7 & 58.1 & 94.7 & 132.6 \\
Crude oil + salts & 6.3 & 27.8 & 63.4 & 109.3 & 167.7 \\
\hline
\end{tabular}
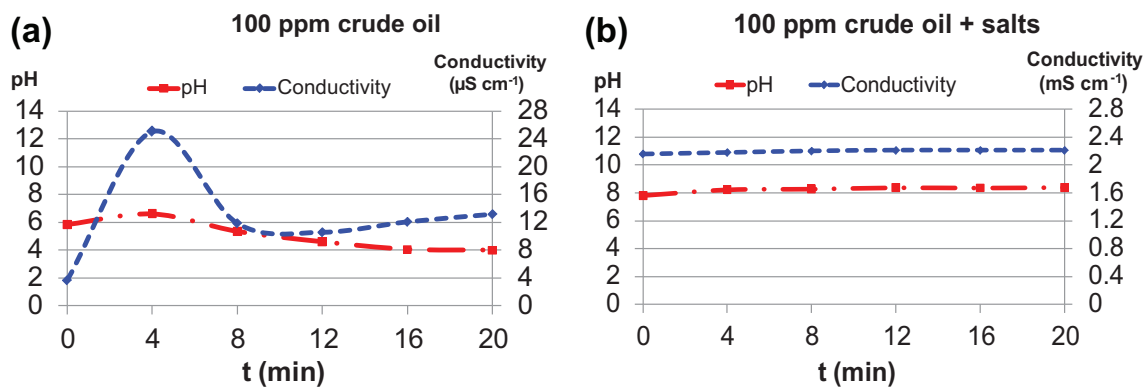

Fig. 1. (a) Effect of ozone treatment on $\mathrm{pH}$ and conductivity of $100 \mathrm{ppm}$ crude oil emulsion and (b) effect of ozone treatment on $\mathrm{pH}$ and conductivity of salt-containing $100 \mathrm{ppm}$ crude oil emulsion.
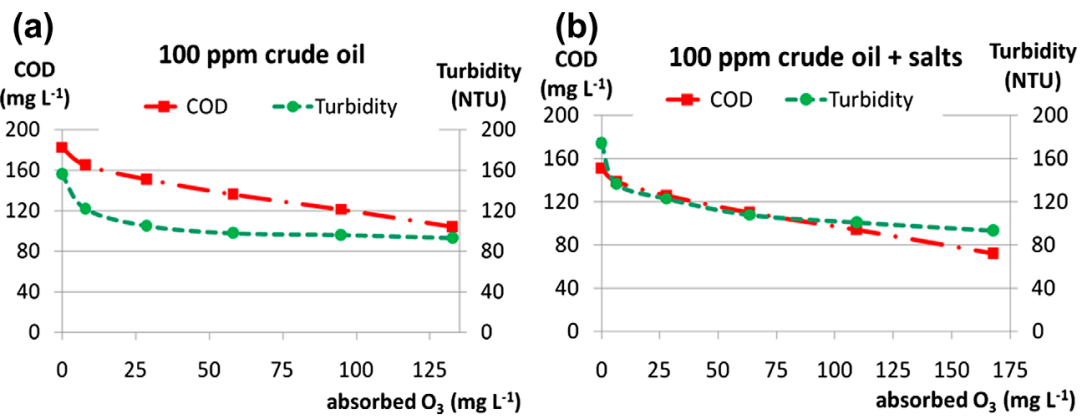

Fig. 2. (a) The PES membrane wettability after filtration and (b) COD retention of crude oil-containing emulsions in presence and absence of salts as a function of ozonation time.

(a)

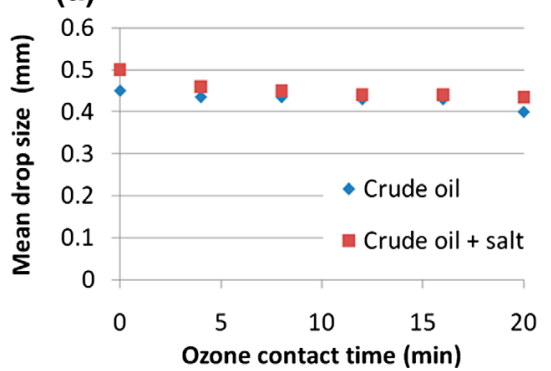

(b)

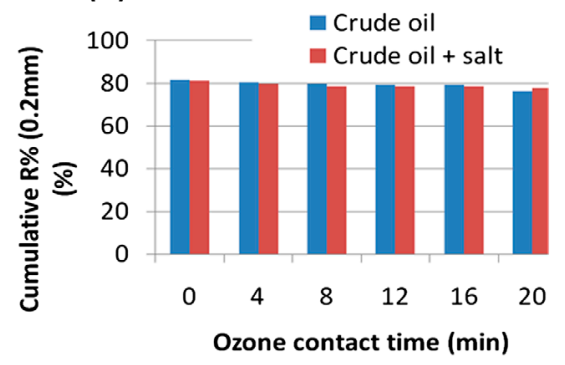

Fig. 3. Changes of COD and turbidity in absence (a) and presence (b) of salts in 100 ppm crude oil (CO) emulsion. 
(a)

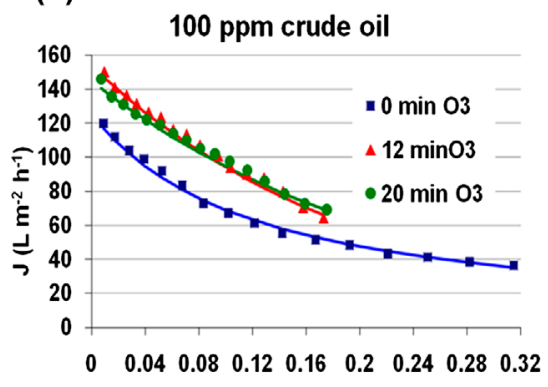

$\mathbf{t}(\mathbf{h})$ (b)

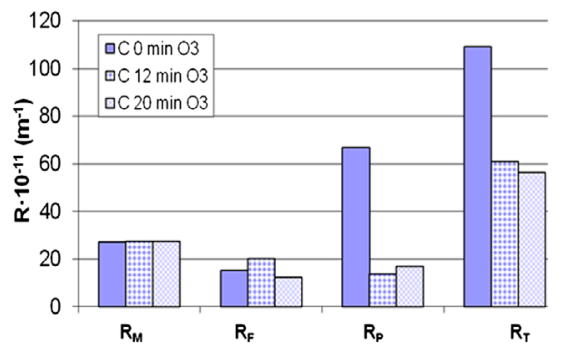

Fig. 4. (a) Effect of ozonation on $100 \mathrm{ppm}$ crude oil emulsion size and (b) ratio of the drops larger than the pore size of the membrane $(0.2 \mu \mathrm{m})$.

(a)

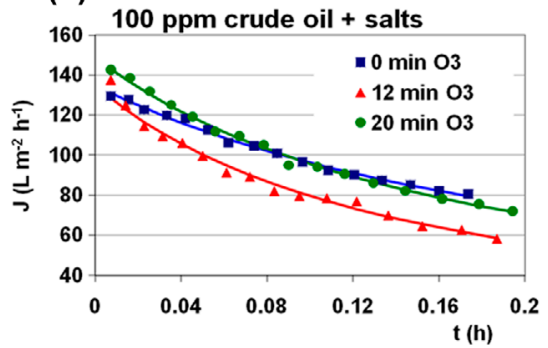

(b)

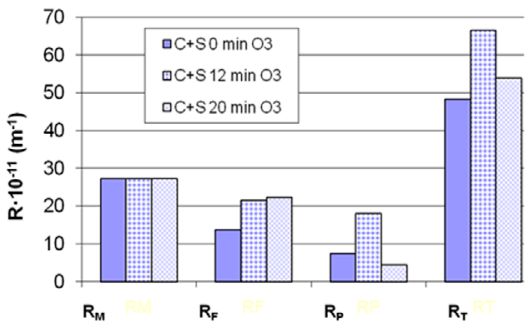

Fig. 5. (a) Effect of ozone pre-treatment on the microfiltration fluxes at crude oil emulsions, (b) membrane resistances obtained from resistanes-in-series model at crude oil and $(\mathrm{C})$ containing emulsions.

(a)

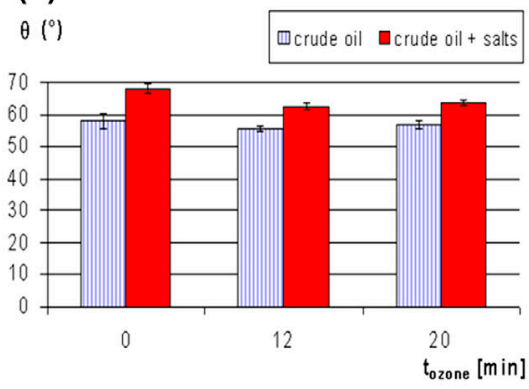

(b)

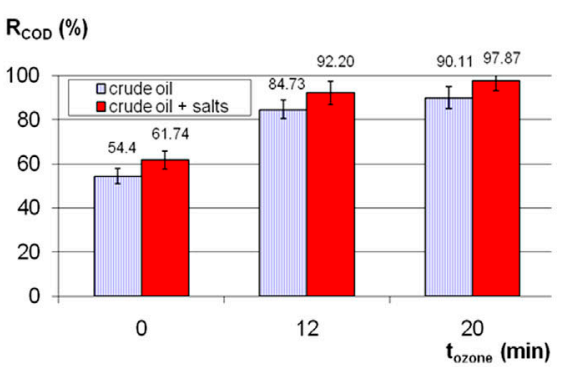

Fig. 6. (a) Effect of ozone pre-treatment the microfiltration fluxes at salt-containing crude oil emulsions and (b) membrane resistances obtained from resistanes-in-series model at salts-containing crude oil $(C+S)$ emulsions.

20-min ozone treatment, the flux was almost the same as in case of the untreated samples. (Fig. 5(a)).

Results obtained with resistances-in-series model showed that the fouling and polarisation layer resistances are in the same order of magnitude. The ozone treatment slightly increased the fouling resistance due to the decreasing droplet sizes and slightly decreased the polarisation layer resistance.
Since ozone treatment changes the chemical nature of the particles in the emulsion (e.g. the polarity of large molecules), the interactions between the solution and the membrane surface can also be changed. In order to get more information about the interactions between oil drops and the membrane, contact angle of distilled water on the surface of used membranes were measured (Fig. 6). 
The wettability of the membrane surface after filtration of salt-containing oil-in-water emulsions was lower than after the filtration of crude oil emulsions. The membrane surface wettabilities were slightly higher after filtration of ozone-treated samples (Fig. 6(a)) both in presence and absence of salts.

The COD retention was found to be higher in the presence of salts (Fig. 6(b)). The COD retention values of untreated samples were lower than it was expected: while about $81 \%$ of the drops are larger than the pore size of the membrane $(0.2 \mu \mathrm{m})$, the COD retentions were only 54.1 and $61.7 \%$ in absence and presence of salts, respectively. It is in accordance with other's results; during cross-flow microfiltration of oil emulsions the droplets may become deformed, and they may penetrate into the pores [5] even though the pore size is smaller than the size of the droplet [8]. The COD retention increased with ozone dose due to oxidative elimination of smaller molecules, and by ozonation by-product formation, which may stabilise the oil droplets and make them less deformable. In presence of salts, the COD retention was higher than in absence of salts. This can be explained partly by changing the droplets size in presence of salts (Fig. 3(a)). On the other hand, the pre-existing and ozone-generated organic acids (e.g. oxalic acid) can react with metal ions forming insoluble precipitates (e.g. calcium oxalate) enhancing the retention. This may explain the higher turbidity of salt-containing emulsions too (Fig. 2).

\section{Conclusions}

Untreated and ozone-treated oil-in-water emulsions (crude oil; $c=100 \mathrm{ppm}$ ) and model oilfield-produced waters were filtered with a 0.2- $\mathrm{m}$ PES MF membrane. The salt content of untreated samples affected the droplet size and the membranes wettability. Pre-ozonation changed the chemical nature of the emulsified particles, causing a change in the interactions between the solution and the membrane surface thereby affecting the filtration parameters both in presence and absence of salts. Ozone oxidises long-chain hydrocarbons to ozonation by-products, which may stabilise the oil droplets and make them less deformable; increasing COD retention.

\section{Acknowledgements}

The authors are grateful for the financial support provided by the OTKA project (project number OTKA K112096) and the Bolyai János Research Fellowship of the Hungarian Academy of Sciences.

\section{References}

[1] M. Erten-Unal, A.B. Gelderloos, J.S. Hughes, A toxicity reduction evaluation for an oily waste treatment plant exhibiting episodic effluent toxicity, Sci. Total Environ. 218 (1998) 141-152.

[2] E.B. da Silva, D. Santos, M.P. de Brito, R.C.L. Guimarães, B.M.S. Ferreira, L.S. Freitas, M.C.V. de Campos, E. Franceschi, C. Dariva, A.F. Santos, M. Fortuny, Microwave demulsification of heavy crude oil emulsions: Analysis of acid species recovered in the aqueous phase, Fuel 128 (2014) 141-147.

[3] F.L. Hua, Y.F. Tsang, Y.J. Wang, S.Y. Chan, H. Chua, S.N. Sin, Performance study of ceramic microfiltration membrane for oily wastewater treatment, Chem. Eng. J. 128 (2007) 169-175.

[4] M. Padaki, R.S. Murali, M.S. Abdullah, N. Misdan, A. Moslehyani, M.A. Kassim, N. Hilal, A.F. Ismail, Membrane technology enhancement in oil-water separation. A review, Desalination 357 (2015) 197-207.

[5] T. Darvishzadeh, V.V. Tarabara, N.V. Priezjev, Oil droplet behavior at a pore entrance in the presence of crossflow: Implications for microfiltration of oil-water dispersions, J. Membr. Sci. 447 (2013) 442-451.

[6] M. Hemmati, F. Rekabdar, A. Gheshlaghi, A. Salahi, T. Mohammadi, Effects of air sparging, cross flow velocity and pressure on permeation flux enhancement in industrial oily wastewater treatment using microfi ltration, Desalin. Water Treat 39 (2012) 33-40.

[7] E. Salehi, S.S. Madaeni, A.A. Shamsabadi, S. Laki, Applicability of ceramic membrane filters in pretreatment of coke- contaminated petrochemical wastewater: Economic feasibility study, Ceram. Int. 40 (2014) 48054810.

[8] A. Ullah, R.G. Holdich, M. Naeem, V.M. Starov, Stability and deformation of oil droplets during microfiltration on a slotted pore membrane, J. Membr. Sci. 401402 (2012) 118-124.

[9] E. Iritani, S. Matsumoto, N. Katagiri, Formation and consolidation of filter cake in microfiltration of emulsion-slurry, J. Membr. Sci. 318 (2008) 56-64.

[10] Y. Zhu, W. Xie, J. Li, T. Xing, J. Jin, pH-induced non-fouling membrane for effective separation of oil-in-water emulsion, J. Membr. Sci. 477 (2015) 131-138.

[11] M. Zare, F.Z. Ashtiani, A. Fouladitajar, CFD modeling and simulation of concentration polarization in microfiltration of oil-water emulsions; Application of an Eulerian Multiphase Model, Desalination 324 (2013) 37-47.

[12] D. Vasanth, G. Pugazhenthi, R. Uppaluri, Cross-flow microfiltration of oil-in-water emulsions using low cost ceramic membranes, Desalination 320 (2013) 8695.

[13] A. Ullah, R.G. Holdich, M. Naeem, V.M. Starov, Shear enhanced microfiltration and rejection of crude oil drops through a slotted pore membrane including migration velocities, J. Membr. Sci. 421-422 (2012) 6974.

[14] A. Fouladitajar, F.Z. Ashtiani, A. Okhovat, B. Dabir, Membrane fouling in microfiltration of oil-in-water emulsions; a comparison between constant pressure blocking laws and genetic programming (GP) model, Desalination 329 (2013) 41-49. 
[15] T. Darvishzadeh, N.V. Priezjev, Effects of crossflow velocity and transmembrane pressure on microfiltration of oil-in-water emulsions, J. Membr. Sci. 423-424 (2012) 468-476.

[16] R.D. Paode, M. Chandrakanth, G.L. Amy, J.T. Gramith, D.W. Ferguson, Ozone versus ozone/ peroxide induced particle destabilization and aggregation: A pilot study, Ozone-Sci. Eng. 17 (2005) 25-51.
[17] I.-S. Chang, C.-M. Chung, S.-H. Han, Treatment of oily wastewater by ultrafiltration and ozone, Desalination 133 (2001) 225-232.

[18] N.N. Li, A.G. Fane, W.S.W. Ho, T. Matsuura, Advanced Membrane Technology and Applications, John Wiley \& Sons, USA, 2008. ISBN 978-0-471-73167-2.

[19] G. Ríos, C. Pazos, J. Coca, Destabilization of cutting oil emulsions using inorganic salts as coagulants, Colloids Surf., A 138 (1998) 383-389. 